\title{
Effects of physical training with different intensities of effort on lipid metabolism in rats submitted to the neonatal application of alloxan
}

Carla Ribeiro*, Lucieli Teresa Cambri, Rodrigo Augusto Dalia, Michel Barbosa de Araújo, José Diego Botezelli, Amanda Christine da Silva Sponton and Maria Alice Rostom de Mello

\begin{abstract}
Background: Type 2 diabetes mellitus (T2DM) is a chronic disease that is characterized by insulin resistance. Its development is directly connected with the inability of insulin to exert its action, not just on carbohydrate metabolism but also on primarily on lipid metabolism. The present study aimed to compare the effects of continuous, intermittent, and strength training on serum and tissue variables on the lipid metabolism of alloxan rats.

Methods: Wistar rats were divided into eight groups: sedentary alloxan (SA), sedentary control (SC), continuous training alloxan (CA), intermittent training alloxan (IA), strength training alloxan (StA), continuous training control (CC), intermittent training control (IC) and strength training control (StC). Alloxan (250 mg/kg bw) was injected into neonatal rats at 6 days of age. The continuous training protocol consisted of 12 weeks of swimming training for 1 uninterrupted hour / day, five days/ week, supporting a load that was 5\% bw. The intermittent training protocol consisted of 12 weeks of swimming training with $30 \mathrm{~s}$ of activity interrupted by $30 \mathrm{~s}$ of rest, for a total of $20 \mathrm{~min} /$ day, five days/ week, supporting a load that was $15 \%$ bw. The strength-training protocol consisted of 12 weeks of training, five days/week with 4 sets of 10 jumps in water with 1 min rest between sets, supporting a load that was a $50 \%$ bw.

Results: At 28 days, the alloxan animals exhibited higher insulin resistance as measured by the disappearance of glucose serum (\% Kitt/min) during the ITT. At 120 days, the sedentary alloxan animals showed higher FFA values than continuous and intermittent training alloxan. In addition, the alloxan animals that underwent intermittent and strength training showed lower FFA values compared to the corresponding controls. The continuous training protocol was less effective than the strength training protocol for reducing the levels of total cholesterol in the alloxan animals. Serum total lipid values revealed that intermittent training increased serum levels in alloxan animals
\end{abstract}

Conclusion: Thus, it was concluded that physical training at different intensities of effort is of great importance in attenuation and control of changes in the lipid metabolism in alloxan animals.

Keywords: Neonatal rats, Alloxan, Exercise training, Lipid metabolism

\footnotetext{
*Correspondence: carla_ef_rc@yahoo.com.br

Institute of Biosciences Physical Education Department, São Paulo State University - (Universidade Estadual Paulista- UNESP), Av: 24-A, 1515 Bela Vista, Rio Claro - São Paulo CEP: 13506-900, Brazil
} 


\section{Introduction}

In recent years, the incidence of type 2 diabetes mellitus (T2DM) has increased considerably [1]. T2MD is a chronic disease that is characterized by insulin resistance $[2,3]$ and Its development is directly associated with the inability of insulin to exert its action, not just on carbohydrate metabolism but also on primarily in lipid metabolism, in addition to its anabolic and anti-catabolic actions $[4,5]$.

Physical exercise has been widely used to protect the body against the decreased responses to the biological actions of insulin in peripheral tissues and to reduce the metabolic changes that are produced by insulin resistance. Physical exercise leads to increased glucose uptake $[6,7]$, particularly in muscle and adipose tissue, by promoting the translocation of Glut-4 $[8,9]$ to the membrane during muscle contraction. Exercise also causes a reduction of body fat, increased oxidation of adipose tissue [10], decreased activity of inflammatory proteins that have a negative effect on insulin action, an improvement in lipid profiles, and increased sensitivity to insulin [8].

Therefore, physical training plays an important role in modulating the metabolic response that is caused by insulin resistance in T2DM $[11,12]$. However, there is a lack of direct evidence regarding the preventive effect of exercise on the corporal issues that comprise T2DM, as such T2DM studies of humans are difficult to realize due to the required intensity of effort and schedule and training protocols. Therefore, animal models provide the most suitable means of studying this disease. Thus, chemically induced diabetes in animals has been widely used as an experimental model for studying complications caused by diabetes [13] and the effects of physical exercise on insulin resistance and fat metabolism.

Oliveira et al. [14], using a neonatal alloxan model, found higher levels of FFA and liver lipids in alloxan animals. These values were reduced after 8 weeks of continuous swim training at moderate intensity, which indicates the importance of physical exercise on fat metabolism. Ribeiro et al. [15] found no change in the FFA content of animals when alloxan was administered in rats up to 6 days old. For streptozotocin-induced diabetes in adult rats, however, the authors found higher FFA concentrations in animals that underwent highintensity acute exercise [16]. After analyzing the lipid metabolism of alloxan adult animals, Moura et al. [17] found no difference in the concentrations of triglycerides, total cholesterol, and FFAs in animals after 44 days of continuous training with moderate intensity swimming compared to controls. Barakat et al. [18] showed that the ability of the livers of alloxan animals to synthesize total lipids, diglycerides, and triglycerides was similar to that of control animals. After 7 days of moderate intensity training on a treadmill, the same result was found. Alloxan-induced diabetes resulted in hypertriglyceridemia in adult animals [19]. Continuous swim exercise at moderate intensity reduced triglyceride levels [19]. The authors have suggested that this change in the triglyceridemia of animals induced by physical training is due to a modulation of lipoprotein lipase activity $[20,21]$.

There is little information available on the effects of neonatal alloxan administration and the application of different physical exercise protocols on lipid metabolism. Therefore, this study aimed to compare the effects of continuous, intermittent, and strength training on serum and tissue variables on the lipid metabolism of alloxan rats.

\section{Materials and methods}

\section{Animals}

Male and female adult Wistar rats (90 days) were used in the study. The Central Animal Laboratory of the Paulista State University (UNESP), Botucatu provided the animals. The rats were housed in the vivarium of the Biodynamic sector of the Department of Physical Education of UNESP, Rio Claro, which was kept at room temperature $\left(25 \pm 1^{\circ} \mathrm{C}\right)$ with a $12 / 12$ hour light/dark photoperiod with lights on from 6:00 to 18:00. The rats were provided free access to water and food (balanced diet for rodents, Purina $\left.{ }^{\circledR}\right)$. The Ethics Committee for Animal Experimentation of the University of Taubaté (Comitê de ética para experimentação animal / Universidade de Taubaté, CEEA/UNITAU) approved the procedures that were adopted for the animals under protocol CEEA/UNITAU No. 019/08.

\section{Neonatal application of alloxan}

At six days of age, male offspring with an average weight of $11.9 \pm 1.2 \mathrm{~g}$ were administered intraperitoneal injections $(250 \mathrm{mg} / \mathrm{kg}$ body weight) of alloxan monohydrate that was dissolved in $0.01 \mathrm{M}$ citrate buffer, $\mathrm{pH} 4.5$ [22], after fasting for 15 hours. Rats of the same age and gender injected with the vehicle (citrate buffer) were used as controls. The neonates were then distributed such that each mother breastfed eight pups.

\section{Design and experimental groups}

At 28 days of age, the offspring comprised 8 groups of 10 animals each, which were observed until 120 days of age (Figure 1).

- Sedentary control (SC): rats injected with citrate buffer that did not subjected training.

- Continuous training control (CC): rats injected with citrate buffer that were subjected to the continuous training program.

- Intermittent training control (IC): rats injected with citrate buffer that were subjected to the intermittent training program. 


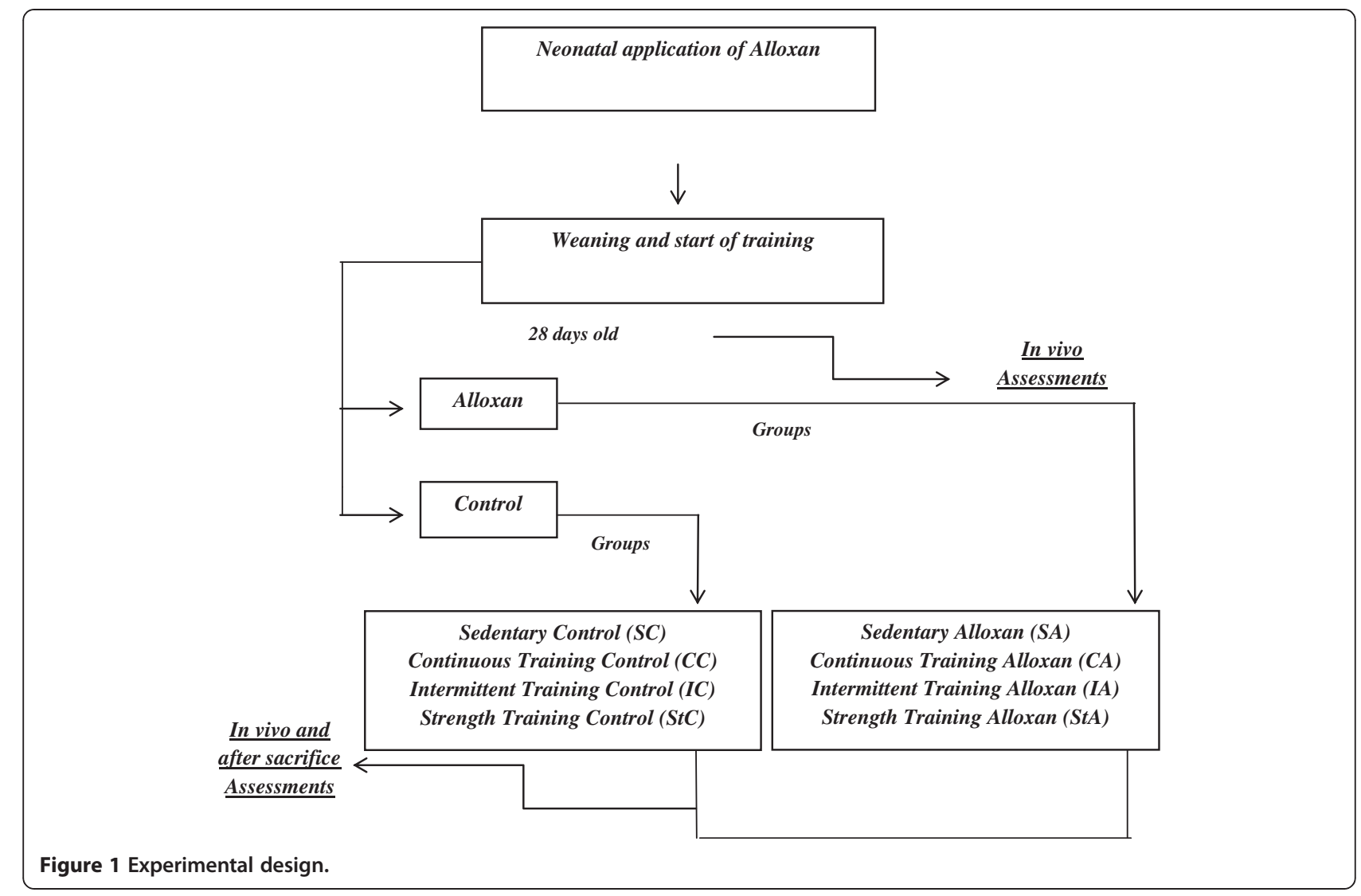

- Strength training control (StC): rats injected with citrate buffer that were subjected to the strength training program.

- Sedentary alloxan (SA): rats injected with alloxan that did not subjected training.

- Continuous training alloxan (CA): rats injected with alloxan that were subjected to the continuous training program.

- Intermittent training alloxan (IA): rats injected with alloxan that were subjected to the intermittent training program.

- Strength training alloxan (StA): rats injected with alloxan that were subjected to the strength training program.

\section{Exercise training}

The animals underwent an initial period of adaptation. First, they were allowed to acclimate to the aquatic environment for 15 minutes. On the following day, the level of water was increased, and the rats were allowed to swim for 15 minutes. On the $3^{\text {rd }}$ day the water level was adjusted to the level at which the rats trained, and they were allowed to swim for 25 minutes. On the $4^{\text {th }}$ day, they swam for 30 minutes with a load attached to the back that was equivalent to $3 \%$ of their body weight. On the $5^{\text {th }}$ day, the duration of the session was increased to 40 minutes with a load equivalent to $5 \%$ of their body weight. Following this adaptation period, the training period was started.

All of the exercise programs were begun upon weaning of the pups and were continued throughout 120 days of study. For the continuous exercise program, animals swam for 1 hour (uninterrupted) each day, 5 days per week, in individual tanks (50 cm high $\mathrm{x} 25$ wide) while supporting a load of $5 \%$ of their body weight. This intensity of effort corresponded to the metabolic aerobic / anaerobic transition for the rats while swimming [23]. For the intermittent program, animals alternated between 30 $\mathrm{s}$ of swimming activity and $30 \mathrm{~s}$ of rest in individual tanks (50 cm high $\mathrm{x} 25$ wide) for a total of 20 minutes per day, 5 days per week, while supporting a load of $15 \%$ of their body weight (adapted from Braga et al. [24] protocol). The total weekly training loads (TWT) of the training protocols were equal. According to Araújo et al. [25], the TWT corresponds to the sum of the training stimuli, which is obtained by taking the product of exercise time ( $\mathrm{t}$ ) and intensity (\%). Thus, in the present study, the continuous training had a TWT of $60 \mathrm{~min} x$ $5 \%=300 \%$, which is equivalent to the intermittent training TWT of $20 \mathrm{~min} \times 15 \%=300$.

The animals that underwent strength training were subjected to four series of 10 jumps in individual tanks 
of water alternated with $1 \mathrm{~min}$ of rest between each set, five days per week, while supporting a load of $50 \%$ of their body weight [26]. The water temperature was maintained at $31^{\circ} \mathrm{C} \pm 1^{\circ} \mathrm{C}$ during the exercise, as this temperature is considered to be thermally neutral in relation to the temperature of rats $[27,28]$.

\section{In vivo assessments Insulin sensitivity}

To estimate insulin sensitivity an insulin tolerance test (ITT) was performed at 28 days. The test consisted of an insulin solution (30 mU/100 g of body weight) that was administered subcutaneously in the dorsal region. Blood samples $(25 \mu \mathrm{L})$ for glucose determination were collected in heparinized capillary tubes via a small incision in the end of the tail after 0, 30, 60, and 120 minutes (Kitt Glucose, Laborlab: CAT n 02200, Guarulhos, SP, Brazil). The single tail incision was sufficient for obtaining all of the samples. The disappearance rate of glucose (Kitt) expressed in \%/minute was calculated using the formula $(0.693 / t / 2)$ X100. Blood glucose level ( $t / 2)$ was calculated using the curve of the least square analysis of the serum glucose levels. The analysis revealed a linear decrease in blood glucose following insulin administration [29].

\section{Stress test}

Stress tests were performed to evaluate the effect of training, and our analysis was focused on blood lactate kinetics at 120 days of age. The rats trained in the continuous protocol swam uninterrupted for $30 \mathrm{~min}$ while supporting a load of $5 \%$ of their body weight. The animals trained in the intermittent protocol were subjected to $30 \mathrm{~s}$ of swimming alternated with $30 \mathrm{~s}$ of rest, totaling 20 min, while supporting a load with $15 \%$ of their body weight. Finally, the rats trained in the strength protocol underwent four series of 10 jumps in the water with 1 min of resting between each set while supporting a load of $50 \%$ of their body weight. For comparison, the sedentary rats were also subjected to the tests described above. Blood samples $(25 \mu \mathrm{L})$ were collected in heparinized capillary tubes to analyze lactate concentrations. Blood was collected at rest, at every 5 minutes of exercise for the continuous protocol, and at every $5 \mathrm{~min}$ of effort in the intermittent protocol. For the strength protocol, collections were made after the completion of each series of jumps and at 5, 7, 9, 13, and 15 minutes after the end of the four series. Blood was collected via a small cut at the distal end of the tail. A single incision at the beginning of the test was sufficient for obtaining all of the samples. Lactate levels were obtained using the enzymatic method [30].

\section{Sacrifice of animals}

At 120 days of age, to obtain the biological material, the animals were sacrificed via decapitation after deeply inducing anesthesia with amobarbital sodium $(15 \mathrm{mg} / \mathrm{kg}$ body weight) without prior fasting 48 hours after the oral glucose tolerance tests and/or 48 hours after the last training session.

\section{Assessments after sacrifice}

Blood Blood samples were collected to verify the concentrations of free fatty acids (FFAs), triglycerides, total cholesterol, and total lipids using a commercial spectrophotometric kit Laborlab $^{\circledR}$, Guarulhos, SP, Brazil).

\section{Tissue}

Adipose tissue The adipose tissue of the posterior, mesenteric, and retroperitoneal subcutaneous regions was removed and weighed for the determination of total lipids. Excisions of the various fat deposits were performed according to [31]. The concentrations of lipids in the deposits were determined using the procedure described by [32].

Liver, heart, and gastrocnemius muscle The concentrations of total lipids were evaluated in the liver, heart, and gastrocnemius.

\section{Statistical analysis}

The data analysis was performed using Student's-t test or a two-way analysis of variance ANOVA followed by the Newman-Keuls post hoc test, where appropriate. In all cases, the levels of significance were preset at $5 \%$ $(\mathrm{p}<0.05)$.

\section{Results}

At 28 days of age, an insulin tolerance test (ITT) was performed to evaluate insulin sensitivity, which was evaluated using the Kitt glucose disappearance rate (\%/min). Alloxan animals exhibited lower disappearance rates compared to controls, which shows the effectiveness of the neonatal administration of alloxan for the installation of clinical picture of insulin resistance (Figure 2).

In addition, stress tests were performed at 120 days of age to evaluate the effect of the different training protocols, continuous, intermittent, and strength, through lactate kinetics (Figure 3). The analysis of the lactate concentrations for the continuously trained alloxan group (CA) revealed higher lactacidemia at rest compared to the corresponding sedentary (SA) and trained (CC) control groups. Differences in the test were also found regarding the intermittent training. According to the lactate kinetics, the sedentary alloxan group (SA) 


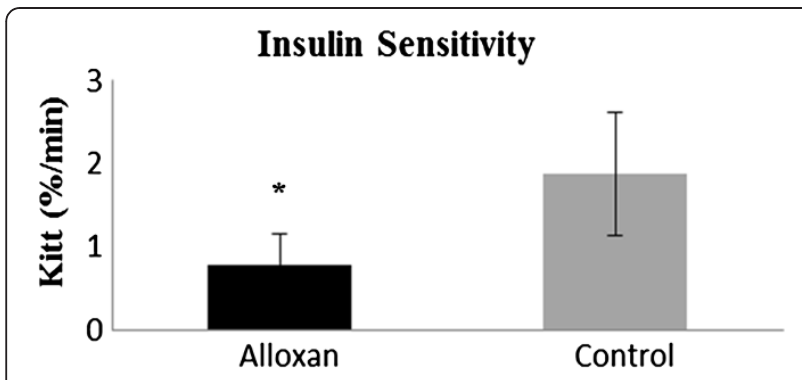

Figure 2 Serum glucose disappearance rate (Kitt, \%/min) during the insulin tolerance test (ITT) at weaning ( 28 days). The results are expressed as the mean $\pm S D, n=10$ animals per group. The symbol * indicates significant difference (Student's t test, $p<0.05$ ) between groups (alloxan and control).

showed higher values than the trained alloxan group (IA), which in turn showed lower concentrations than the corresponding control group (IC) at rest. Furthermore, the sedentary control group (SC) showed lower lactate concentrations at the end of the test compared to the trained control (IC). Lactacidemia analysis of the animals submitted to the strength training protocol revealed that the sedentary control animals (SC) had higher concentrations throughout the test than the trained control animals (StC). The sedentary alloxan animals (SA) showed higher values than the sedentary control (SC) and alloxan trained (StA) groups 5 min after termination of the test and after the third series of jumps, respectively. Nine minutes after the test, the trained alloxan animals (StA) showed higher concentrations than the corresponding control group (StC), and increased lactacidemia was found in the alloxan and sedentary animals.

FFA, triglyceride, total cholesterol, and total serum lipids levels are shown in Table 1. Regarding FFA values, the sedentary alloxan animals (SA) showed higher values than the alloxan animals after continuous training and intermittent swimming (CA and IA). The control group after continuous training (CC) had lower FFA values than the sedentary control (SC), intermittent training (IC), and strength (StC) groups. Moreover, alloxan animals that underwent intermittent (IA) and strength (StA) training showed lower values of FFAs compared to the corresponding controls (IC and $\mathrm{StC}$ ). No differences were found among the triglyceride concentrations. The continuous training protocol was less effective than the strength training protocol in reducing cholesterol levels in alloxan animals $(\mathrm{CA}>\mathrm{StA})$. Total serum lipid values also showed that intermittent training increased serum levels in alloxan animals (IA > SA, CA, StA and IC). With regard to the lipids assessed in the retroperitoneal, mesenteric, and subcutaneous portions of the animals adipose tissue, no differences were found (Table 2).

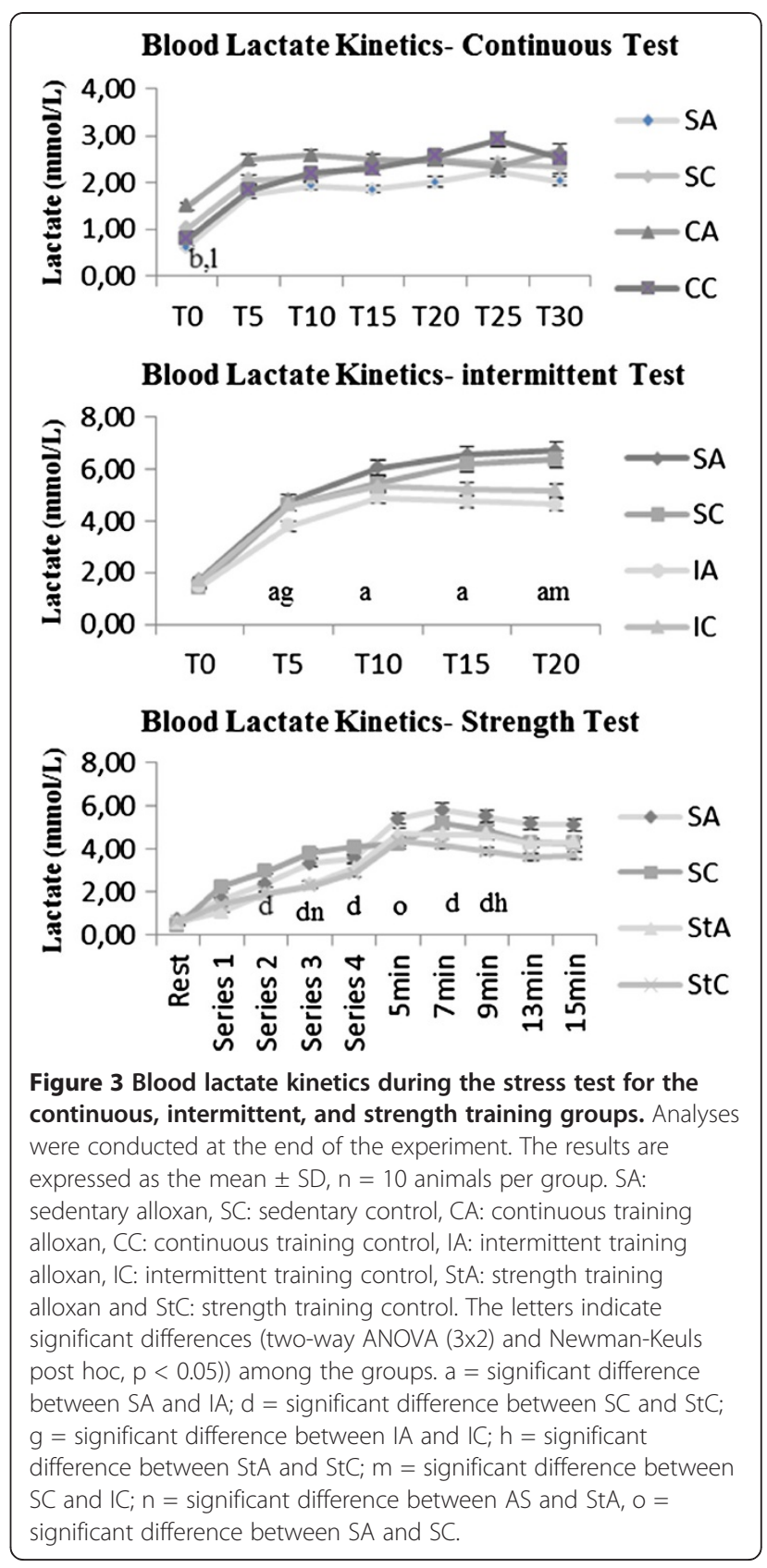

Table 3 summarizes the results relating to gastrocnemius muscle, heart, and liver tissue lipids that were measured in the animals at 120 days of age. Differences were found only in the liver; the alloxan animals that were subjected to continuous swim training showed lower values (CA <SA, IA, StA, and CC), which demonstrates the importance of aerobic training for controlling possible lipid changes caused by insulin resistance in liver tissue.

\section{Discussion}

Type 2 Diabetes mellitus (T2DM) is a chronic disease that affects approximately $90-95 \%$ of diabetics [5] and 
Table 1 FFA, triglyceride, total cholesterol, and serum lipid levels measured at 120 days of age

\begin{tabular}{|c|c|c|c|c|c|c|c|c|}
\hline Variables & SA & SC & CA & $\mathrm{CC}$ & IA & IC & StA & StC \\
\hline \multirow[t]{2}{*}{ Serum FFA $(\mu \mathrm{Eq} / \mathrm{L})$} & $539.2 \pm$ & $498.6 \pm$ & $392.5 \pm$ & $334.9 \pm$ & $390.0 \pm$ & $564.8 \pm$ & $438.2 \pm$ & $659.1 \pm$ \\
\hline & $116.5 \mathrm{ab}$ & $111.7_{c d}$ & 111.3 & $105.6_{\mathrm{ef}}$ & $92.4 \mathrm{~g}$ & 120.7 & $94.4 \mathrm{~h}$ & 78.7 \\
\hline \multirow[t]{2}{*}{ Triglycerides (mg / dL) } & $215.3 \pm$ & $245.0 \pm$ & $274.0 \pm$ & $197.5 \pm$ & $278.3 \pm$ & $262.7 \pm$ & $228.5 \pm$ & $280.3 \pm$ \\
\hline & 47.8 & 69.2 & 67.1 & 57.5 & 93.9 & 58.2 & 51.8 & 106.1 \\
\hline \multirow[t]{2}{*}{ Total cholesterol (mg / dL) } & $85.4 \pm$ & $89.1 \pm$ & $88.5 \pm$ & $85.9 \pm$ & $84.9 \pm$ & $77.0 \pm$ & $70.4 \pm$ & $79.9 \pm$ \\
\hline & 14.8 & 14.2 & $21.1 \mathrm{i}$ & 15.3 & 9.1 & 6.7 & 7.1 & 10.6 \\
\hline \multirow[t]{2}{*}{ Total lipids (mg / dL) } & $345.5 \pm$ & $328.0 \pm$ & $379.7 \pm$ & $315.9 \pm$ & $444.1 \pm$ & $362.9 \pm$ & $330.1 \pm$ & $329.1 \pm$ \\
\hline & $53.3 \mathrm{a}$ & 73.6 & $58.3_{j}$ & 53.6 & $107.7 \mathrm{~g} \mathrm{k}$ & 54.7 & 53.3 & 78.8 \\
\hline
\end{tabular}

The results expressed as the mean \pm SD, $n=10$ animals per group. SA: sedentary alloxan, SC: sedentary control, CA: alloxan continuous training, DC: continuous training control, IA: alloxan intermittent training, IC: intermittent training control, StA: alloxan strength training and StC: strength training control. The letters indicate significant differences (two-way ANOVA $3 \times 2$ ) and Newman-Keuls post hoc, $p<0.05$ )) among the groups. $a=$ significant difference between $S A$ and $I A$; $b=$ significant difference between $\mathrm{SA}$ and $\mathrm{CA} ; \mathrm{C}=$ significant difference between $\mathrm{SC}$ and $\mathrm{CC} ; \mathrm{d}=$ significant difference between $\mathrm{SC}$ and $\mathrm{StC}$; e $=$ significant difference

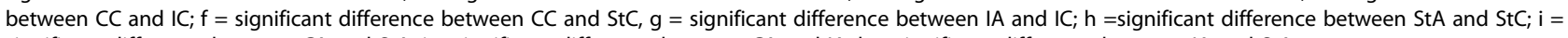
significant difference between $C A$ and $S t A ; j=$ significant difference between CA and IA; $k=$ significant difference between IA and StA.

has grown considerably in recent years. The cause of T2DM is a combination of a resistance to insulin action as well as compensatory responses of hormone secretion. This combination results in alterations in the metabolism of carbohydrates, lipids, and proteins due to a deficient action of insulin in peripheral target tissues, which have a decreased response at one or more points of the hormone signaling pathway $[4,5]$. The risk of developing type 2 diabetes increases with age, obesity, and physical inactivity, all of which contribute to a metabolism imbalance, principally in lipid profiles. The present study aimed to compare the effects of continuous, intermittent, and strength training on serum and tissue variables on the lipid metabolism of alloxan rats.

The present study data showed an efficacy of neonatal alloxan administration, proved by the changes in insulin sensitivity in alloxan animals when assessing the serum glucose disappearance rate in ITT after 28 days of age. These findings are consistent with previous studies conducted using a neonatal alloxan model [12,33,34], which showed lower insulin sensitivity in alloxan animals.

Chronic physical training has an important role in improving insulin sensitivity $[35,36]$ and the lipid profile [8] in T2DM, but the optimal level of effort that should be applied remains unknown. The present study used three physical training protocols with different intensities of effort to evaluate the effects of aerobic and anaerobic capacity on alloxan animals.

Assessments of aerobic capacity are performed using procedures that investigate a transition zone during exercise to ascertain where there is a predominance of aerobic metabolism over anaerobic metabolism in the supply of adenosine triphosphate to muscle activity. The procedures utilize an analysis of blood lactate concentration as a metabolic parameter because it is a reliable measure of the transition for characterizing the chronic effects of training [37] as well as the effort involved. In the present study, a stress test was conducted to measure lactacidemia in animals after 12 weeks of continuous, intermittent, and strength swimming.

No differences were found in lactate kinetics among the groups that underwent the continuous training protocol. These findings are consistent with Ribeiro et al. [38], who conducted a study using a neonatal alloxan model that demonstrated similar lactacidemia among groups. The response of sedentary animals to the test could be interpreted as moderate intensity with a predominance of aerobic metabolism, given the values of lactate that were

Table 2 Adipose tissue lipids assessed in the retroperitoneal, mesenteric, and subcutaneous portions of the animals at 120 days

\begin{tabular}{lllllllll}
\hline Lipids Adipose Tissue & SA & SC & CA & CC & IA & IC & StA & StC \\
\hline Retroperitoneal (Mg/100 $\mathbf{~ m g ) ~}$ & $62.6 \pm$ & $54.2 \pm$ & $57.0 \pm$ & $62.5 \pm$ & $53.2 \pm$ & $49.5 \pm$ & $60.1 \pm$ & $55.3 \pm$ \\
\cline { 2 - 8 } & -11.7 & 0.1515 .0 & 17.8 & 9.7 & 8.6 & 7.5 & 16.0 & 16.0 \\
\hline Mesenteric (Mg/100 $\mathbf{~ g g ) ~}$ & $44.5 \pm$ & $43.6 \pm$ & $43.6 \pm$ & $36.7 \pm$ & $42.0 \pm$ & $38.0 \pm$ & $36.7 \pm$ & $42.5 \pm$ \\
\cline { 2 - 8 } & 11.4 & 11.4 & 10.2 & 10.5 & 7.4 & 3.2 & 4.3. & 8.7 \\
\hline Subcutaneous (Mg/100 $\mathbf{~ m g ) ~}$ & $43.2 \pm$ & $43.0 \pm$ & $41.1 \pm$ & $40.7 \pm$ & $37.8 \pm$ & $42.8 \pm$ & $38.9 \pm$ & $32.5 \pm$ \\
\cline { 2 - 8 } & 8.0 & 9.4 & 8.0 & 12.0 & 6.8 & 6.0 & 6.7 & 4.2 \\
\hline
\end{tabular}

The results are expressed as the mean \pm SD, $n=10$ animals per group. SA: sedentary alloxan, SC: sedentary control, CA: alloxan continuous training, CC: continuous training control, IA: alloxan intermittent training, IC: intermittent training control, StA: alloxan strength training and StC: strength training control. The letters indicate significant differences (two-way ANOVA $(3 \times 2)$ and Newman-Keuls post hoc, $\mathrm{p}<0.05)$ ) among the groups. 
Table 3 Gastrocnemius muscle, heart, and liver tissue lipids measured in animals at 120 days of age

\begin{tabular}{|c|c|c|c|c|c|c|c|c|}
\hline Lipids & SA & SC & CA & $\mathrm{CC}$ & IA & IC & StA & StC \\
\hline \multirow[t]{2}{*}{ Gastrocnemius muscle (Mg/100 mg) } & $3.0 \pm$ & $2.6 \pm$ & $2.9 \pm$ & $2.4 \pm$ & $2.6 \pm$ & $2.6 \pm$ & $2.7 \pm$ & $2.4 \pm$ \\
\hline & 0.8 & 0.5 & 0.8 & 0.4 & 0.5 & 0.8 & 0.4 & 0.5 \\
\hline \multirow[t]{2}{*}{ Liver (Mg/100 mg) } & $5.7 \pm$ & $5.0 \pm$ & $4.5 \pm$ & $5.8 \pm$ & $5.9 \pm$ & $5.5 \pm$ & $5.7 \pm$ & $5.4 \pm$ \\
\hline & $1.0_{\mathrm{b}}$ & 0.9 & $0.9 i_{j}$ & 0.9 & 0.9 & 0.6 & 0.7 & 0.6 \\
\hline \multirow[t]{2}{*}{ Heart (Mg/100 mg) } & $5.2 \pm$ & $5.5 \pm$ & $7.2 \pm$ & $6.2 \pm$ & $6.3 \pm$ & $6.3 \pm$ & $6.5 \pm$ & $6.2 \pm$ \\
\hline & 0.8 & 1.4 & 2.1 & 1.1 & $6.3 \pm$ & $1.6 z$ & 1.9 & 0.9 \\
\hline
\end{tabular}

The results are expressed as the mean \pm SD, $n=10$ animals per group. AS: sedentary alloxan, SC: sedentary control, CA: alloxan continuous training, CC: continuous training control, IA: alloxan intermittent training, IC: intermittent training control, StA: Alloxan strength training and StC: Strength training control. The letters indicate significant differences ((two-way ANOVA $(3 \times 2)$ and post hoc Newman-Keuls, $p<0.05)$ ) among the groups. $b=$ significant difference between AS vs. $C A ; i=$ significant difference between $C A$ vs. St $A ; j=$ significant difference between $C A$ vs. IA; I = significant difference between $C A$ vs. CC.

achieved and the moderate intensity at the start of the training program. For the intermittent training protocol, although there was the same total weekly load as in the continuous training protocol, a lower lactate disappearance rate in sedentary animals was found, which showed that training had an effect. By measuring the lactate kinetics related to strength training, a higher degree of lactacidemia in sedentary animals compared to controls was found throughout the test, which demonstrates the positive effect of the applied training. These results confirm the chronic effect of exercise in addition to demonstrating a positive response of alloxan animals to different protocols and intensities of effort.

Due to the relationship between changes in insulin sensitivity and lipid metabolism in T2DM and the role of physical exercise, the present study also assessed the animals lipid profile.

High levels of circulating FFAs are correlated with lower phosphorylation and insulin activation (IRS/PI3q) [39]. The presence of FFAs provides a direct relationship with insulin resistance that may result from the accumulation of triglycerides in muscle and liver. Furthermore, the increase of these metabolites due to the oxidation of fat in muscle is capable activating protein kinase $\mathrm{C}$ (PKC) and inducing serine phosphorylation of the insulin receptor (IR) and its substrates, which are important mechanisms that explain the relationship between the accumulation of fat tissue and resistance to insulin $[39,40]$. The present study thus assessed the serum concentrations of FFAs, triglycerides, total cholesterol, and total lipids in addition to lipid levels in adipose tissue, the gastrocnemius muscle, the liver, and the heart.

The serum concentration of FFAs showed a higher concentration in sedentary alloxan animals, but a reduction in the level was found after continuous and intermittent swim training. Additionally, intermittent and strength training were more effective in reducing the level of fatty acids in alloxan animals than in controls. Oliveira et al. [14] found similar results in a neonatal alloxan model. Alloxan animals showed higher levels of FFAs that diminished after continuous swimming. Stolen et al. [41] found results in $\mathrm{db} / \mathrm{db}$ animals that were similar to the FFA concentrations after 13 weeks of intermittent training. Ghelfi et al. [42] found no differences in the concentrations of FFAs in type 1 diabetic subjects after intermittent training of high and moderate intensity. Similar results were found in the serum concentrations of FFAs in alloxan-induced diabetic adult animals [17]. Holten et al. [43] found similar results in a study of type 2 diabetic subjects after strength training. Thus, it is noted that the training protocols applied in the current study were effective in reducing the accumulation of serum FFAs in the animals. Therefore, they likely play an important role in the prevention and treatment of metabolic disturbances in lipid metabolism that are caused by insulin resistance in T2DM. No change was observed between the groups in the concentration of triglycerides. This result differs from the study of alloxan adult animals [18], which reported the animals having lower concentrations of triglycerides after 7 days of training on a treadmill. In the present study, strength training was more effective in reducing total cholesterol levels in alloxan animals, and strength and continuous training were better for the maintenance of total serum lipids. In an experimental model of alloxan-induced diabetes in adult animals, Moura et al. [17] found no significant differences in serum cholesterol levels even after 44 days of continuous training at moderate swimming intensity. In a study using Zucker Diabetic Fatty (ZDF) rats as a T2DM model, diabetic animals had reduced serum cholesterol levels after 12 weeks of swim training at moderate intensity, suggesting the importance of physical training on the lipid profile of T2DM [44].

Many individuals with T2DM are overweight or obese. Thus, their distribution [45] and accumulation of lipids in adipose tissue differ. Therefore, analyses of lipid levels in the adipose tissue in the retroperitoneal, mesenteric, and subcutaneous regions of rats were performed, although no differences were found in the concentrations of these lipids.

Obesity and alterations in the lipids metabolism has been shown as a cause of insulin resistance $[46,47]$. In 
recent years studies have shown a relationship between organ dysfunction and lipids storage in tissues such as liver, heart, pancreas, and skeletal muscle [48]. It is known that exercise training can reduce the changes in lipid metabolism of high-risk subjects for development of T2DM [49].

Therefore, the present study also evaluated total lipid levels in the gastrocnemius muscle, liver, and heart. Differences were noted only in liver tissue for alloxan animals that underwent continuous training, which showed lower concentrations. These results corroborate with those of Oliveira et al. [14] who, using the same neonatal alloxan model, reported a higher use of lipids in the liver after physical training, thereby reducing the amount in the tissue. Moura et al. [17] found similar data in a type 1 diabetes experimental model, which highlights the importance of exercise in the control of total lipids in liver tissue.

In summary, physical training at different intensities of effort and on different schedules was key in the reduction of lipid levels and control of changes in lipid metabolism in alloxan animals. It may therefore be concluded that both high and moderate intensity training were effective in improving the lipid profile of alloxan animals. Therefore, exercise can play an important role in the prevention and treatment of metabolic alterations in lipid metabolism that are caused by insulin resistance T2DM.

\section{Competing interests}

The authors declare that they have no competing interests.

\section{Authors' contributions}

CR conceived the study, developed the study protocol, reviewed the references, collected and analyzed the data, and wrote the paper. LTC, RAD, MBA, JDB and ACSS, participated in the design of the study, reviewed the manuscript, collected the data, and collaborated on the biochemical dosages. MARM conceived the study, participated in its design and coordination and helped in the drafting of the manuscript. All authors read and approved the submission of the final manuscript.

\section{Acknowledgments}

We are thankful Clarice Y Sibuya, Eduardo Custódio and José Roberto R. Silva for their excellent technical assistance. This research was supported by the Foundation for Research Support of São Paulo (FAPESP, process 09/51538-5), the Coordenação de Aperfeiçoamento de Ensino Superior (CAPES), and the National Council of Scientific and Technological Development - CNPq.

Received: 15 August 2012 Accepted: 9 October 2012

Published: 15 October 2012

\section{References}

1. American Diabetes Association: Standards of medical care in diabetes. Diabetes Care 2010, 33:62-69.

2. Hayashia T, Hiranoa T, Yanamotoa T, Itob Y, Adachi M: Intensive insulin therapy reduces small dense low-density lipoproteinparticles in patients with type 2 diabetes mellitus: relationship totriglyceride-rich lipoprotein subspecies. Metabolism 2006, 55:879-884.

3. American Diabetes Association: Standards of medical care in diabetes. Diabetes Care 2011, 34:62-69.

4. May ME, Buse MG: Effects of branched-chain amino acids on protein turnover. Diabetes Metab Rev 1989, 5:227-245.

5. American Diabetes Association: Standards of medical care in diabetes. Diabetes Care 2012, 35:64-71.
6. Thyfault JP: Setting the stage: Possible mechanisms by which acute contraction restores insulin sensitivity in muscle. Am J Physiol-Reg / 2008, 294:1103-1110.

7. Venables MC, Jeukendrup AE: Endurance training and obesity: effect on substrate metabolism and insulin sensitivity. Med Sci Sport Exer 2008, 40:495-502.

8. Misra A, Alappan NK, Vikram NK, Goel K, Gupta N, Mittal K, Bhatt S, Luthra K: Effect of supervised progressive resistance-exercise training protocol on insulin sensitivity, glycemia, lipids, and body composition in Asian Indians with type 2 diabetes. Diabetes Care 2008, 31:1282-1287.

9. Tsukumo DM, Carvalho-filho MA, Carvalheira JB, Prada PO, Hirabara SM, Schenka AA: Loss-of-function mutation in toll-like receptor 4 prevents diet-induced and insulin resistance. Diabetes 2007, 56:1986-1998.

10. Solomon TP, Sistrun SN, Krishnan RK, LF Da, Marchetti CM, O'Carroll SM, O'Leary VB, Kirwan JP: Exercise and diet enhance fat oxidation and reduce insulin resistance in older obese adults. J Appl Physiol 2008, 104:1313-1319.

11. Hawley JA, Lessard SJ: Exercise training-induced improvements in insulin action. Acta Physiol 2008, 192:127-135.

12. Sigal RJ, Kenny GP, Boule NG, Wells GA, Fortier M, Reid RD, Tulloch H, Coyle $D$, Phillips $P$, Jennings A, Jaffey J: Effects of aerobic training, resistance training, or both on glycemic control in type 2 diabetes: a randomized trial. Intern Med 2007, 147:357-369.

13. Srinivasan $K$, Ramarao P: Animal models in type 2 diabetes research: an overview. Indian J Med Res 2007, 3:451-472.

14. Oliveira CAM, Luciano E, Mello MAR: The role of exercise on long- term effects of alloxan administered in neonatal rats. Exp Physiol 2004, 90:79-86.

15. Ribeiro C, Oliveira CAM, Luciano E, Mello MAR: Diabetes evolution in rats after neonatal treatment with alloxan. Res Commun Mol Pathl 2005, 118:29-46.

16. Ferreira LDMC-B, Brau L, Nikolovski S, Raja G, Palmer TN, Fournier PA: Effect of streptozotocin-induced diabetes on glycogen resynthesis in fasted rats post-high-intensity exercise. Am J Physiol - Endoc M 2001, 280:83-91.

17. Moura LP, Puga G, Beck WR, Teixeira IP, Ghezzi AC, Silva GA, Mello MAR: Exercise and spirulina control non-alcoholic hepatic steatosis and lipid profile in diabetic Wistar rats. Lipids Health Dis 2011, 10:77.

18. Barakat HA, Carpenter JW, Lennon YA, Hanna WR Jr, O'Brien KF, Dohm GL: The effects of exercise on lipogenic enzyme activity and glyceride synthesis by liver homogenates of diabetic rats. Metabolism 1987, 36:983-987.

19. Leme JACA, Araújo MB, Moura LP, Gomes RJ, Moura RF, Rogatto GP, Mello MAR, Luciano E: Effects of physical training on serum and pituitary growth hormone contents in diabetic rats. Pituitary 2009, 12:304-308

20. Kraus WE, Houmard JA, Duscha BD, Knetzger KJ, Wharton MB, McCartney JS, Bales CW, Henes S, Samsa GP, Otvos JD, Kulkarni KR, Slentz CA: Effects of the amount and intensity of exercise on plasma lipoproteins. $N$ Engl J Med 2002, 19:1483-1492.

21. Hamilton MT, Areiqat E, Hamiilton DG, Bey L: Plasma triglyceride metabolism in humans and rats during aging and physical inactivity. Int J Sport Nutr Exerc Metab 2001, 11(Suppl):97-104.

22. Luciano E, Lima FB: Metabolismo de ratos diabéticos treinados submetidos ao jejum e ao exercício agudo. Rev Cienc Biomed 1997, 18:47-60.

23. Gobatto CA, Mello MAR, Sibuya CY, Azevedo JRM, Santos LA, Kokubun E: Maximal lactate steady state in rats submitted to swimming exercise. Comp Biochem Phys 2001, 30:21-27.

24. Braga $L R$, Mello MAR, Gobatto CA: Exercício contínuo e intermitente: efeitos do treinamento e do destreinamento sobre a gordura corporal de ratos obesos (Continuous and intermittent exercise: effects of training and detraining on body fat in obese rats). Arch Latinoam Nutr 2004, 54:58-65.

25. Araújo GG, Papoti M, Manchado-Gobatto FB, Mello MAR, Gobatto CA: Padronização de um protocolo experimental de treinamento periodizado em natação utilizando ratos wistar (standardization of an experimental protocol of intermittent swimming training using wistar rats). Rev Bras Med Esporte (Br J Sport Med) 2010, 16:51-56.

26. Roggato GP, Oliveira CAM, Faria MC, Luciano E: Respostas metabólicas agudas de ratos wistar ao exercício intermitente de saltos (Acute metabolic responses of Wistar rats to intermittent jumping exercise). Motriz 2004, 10:61-66. 
27. Azevedo JRM, Azevedo JRM: Determinação de parâmetros bioquímicos em ratos sedentários e treinados após exercício agudo de natação (Determination of biochemical parameters in sedentary and trained rats after acute swimming exercise). State University of Campinas Department of Physiology and Biophysics: PhD thesis; 1994.

28. Pauli JR: Efeitos do treinamento físico sobre aspectos endócrino-metabólicos de ratos administrados com dexametasona (Effects of physical training on endocrine-metabolic aspects of rats administered dexamethasone). Institute of Biosciences, State University Paulista, Rio Claro: PhD thesis; 2005.

29. Lundbaeck K: Intravenous glucose tolerance test the tool in the diagnosis and definition of diabetes mellitus. Brit Med J 1962, 2:1507-1513.

30. Engel RC, Jones JB: Causes and elimination of erratic blanks in enzymatic metabolic assays involving the use of NAD+ in alkaline hydrazine buffers: improved conditions for assay of 1-glutamate, 1- lactate and other metabolites. Anal Biochem 1978, 88:475-484.

31. Cinti S: The adipose organ. Prostagl Leukotr Essent Fatty Acids 2005, 73:9-15.

32. Nogueira DM, Strufaldi B, Hirata MH, Abdalla DSP, Hirata RDC: Métodos de bioquímica clínica: técnico-interpretação. [Clinical biochemistry methods: technical-interpretation]. São Paulo, Pancast:; 1990.

33. Contarteze RVL, Mota CSA, Oliveira CAM, Leme JACA, Bottcher LB, Mello MAR, Luciano E: Exercise test and glucose homeostasis in rats treated with alloxan during the neonatal period or fed a high calorie diet. J Diabetes 2009, 1:65-72.

34. Ribeiro C, Cambri LT, Dalia RA, Araújo MB, Leme JACA, Moura RF, Voltarelli FA, Mello MAR: Continuous and intermittent exercise training and glucose metabolism in neonatal alloxan administered rats. J Endocrinol Metabol 2011, 1:101-112

35. Castaneda C: Type 2 diabetes mellitus and exercise. NCC 2001, 3:349-358.

36. Castaneda C, Layne LE, Orians LM, Gordon PL, Walsmith J, Foldvari M, Roubenoff R, Tucker KL, Nelson ME: A randomized controlled trial of resistance exercise training to improve glycemic control in older adults with type 2 diabetes. Diabetes Care 2002, 25:2335-2341.

37. Billat VL, Sirvent $P, P y ~ G$, Koralsztein JP, Mercier J: The concept of maximal lactate steady state: a bridge between biochemistry, physiology and sport science. Sports Med 2003, 33:407-426.

38. Ribeiro C, Mota CSA, Voltarelli FA, Araújo MB, Botezelli JD, Oliveira CAM, Mello MAR: Effects of moderate intensity physical training in neonatal alloxan- administered rats. J Diabetes Metabo/ 2010, $1: 1-5$.

39. Shulman Gl: Unraveling the cellular mechanism of insulin resistance in humans: new insights from magnetic resonance spectroscopy. Physiology 2004, 19:183-190.

40. Savage DB, Petersen KF, Shulman Gl: Disordered lipid metabolism and the pathogenesis of insulin resistance. Physiol Rev 2007, 87:507-520.

41. Stolen TO, Hoydal MA, Kemi OJ, Catalucci D, Ceci M, Aasum E, Larsen T, Rolim N, Condorelli G, Smith GL, Wisloff U: Interval training normalizes cardiomyocyte function, diastolic Ca2+ control, and SR Ca2+ release synchronicity in a mouse model of diabetic cardiomyopathy. Circ Res 2009, 105:527-536.

42. Guelfi KJ, Ratnam N, Smythe GA, Jones TW, Fournier PA: Effect of intermittent high-intensity compared with continuous moderate exercise on glucose production and utilization in individuals with type 1 diabetes. Am J Physiol Endocrinol Metab 2007, 292:865-870.

43. Holten MK, Zacho M, Gaster M, Juel C, Wojtaszewski JF, Dela F: Strength training increases insulin-mediated glucose uptake, GLUT4 content, and insulin signaling in skeletal muscle in patients with type 2 diabetes. Diabetes 2004, 53:294-305.

44. Lemos ET, Pinto R, Oliveira J, Garrido P, Sereno J, Mascarenhas-Melo F, Páscoa-Pinheiro J, Teixeira F, Reis F: Differential effects of acute (extenuating) and chronic (training) exercise on inflammation and oxidative stress status in an animal model of type 2 diabetes mellitus. Mediators Inflamm 2011, 2011:1-7.

45. Gallagher D, Kelley DE, Yim JE, Spence N, Albu J, Boxt L, Pi-Sunyer FX, Heshka S: Adipose tissue distribution is different in type 2 diabetes. Am J Clin Nutr 2009, 89:807-814
46. Boden G: Obesity, free fatty acids, and insulin resistance. Cur Opin Endocrinol Diabetes 2001, 8:235-239.

47. Boden G, Lebed B, Schatz M, Homko C, Lemieux S: Effects of acute changes of plasma free fatty acids on intramyocellular fat content and insulin resistance in healthy subjects. Diabetes 2001, 50:1612-1617.

48. Muoio DM, Newgard CB: Obesity-related derangements in metabolic regulation. Annu Rev Biochem 2006, 75:367-401.

49. Petković-Košćal M, Damjanov $\mathrm{V}$, Djonović $\mathrm{N}$ : Influence of moderate physical activity on the levels of plasma lipoproteins in subjects with impaired glucose tolerance. Srp Arh Celok Lek 2012, 140:51-57.

doi:10.1186/1476-511X-11-138

Cite this article as: Ribeiro et al.: Effects of physical training with different intensities of effort on lipid metabolism in rats submitted to the neonatal application of alloxan. Lipids in Health and Disease 2012 $11: 138$.

\section{Submit your next manuscript to BioMed Central and take full advantage of:}

- Convenient online submission

- Thorough peer review

- No space constraints or color figure charges

- Immediate publication on acceptance

- Inclusion in PubMed, CAS, Scopus and Google Scholar

- Research which is freely available for redistribution 